\title{
Tuberculosis primaria de la musculatura esquelética
}

\section{Primary skeletal muscle tuberculosis}

\author{
Bouchentouf Rachidl' y Koulali Idrissi Khalid²
}

Rachid B, Khalid KI. Tuberculosis primaria de la musculatura esquelética. Rev Soc Peru Med Interna. 2018;32(2):63-65.

https://doi.org//0.36393/spmi.v32i 2.220

\section{RESUMEN}

La localización muscular primaria de la tuberculosis es una presentación clínica inusual y extremadamente rara sobretodo en pacientes inmunocompetentes. Presentamos el caso de un paciente de 22 años con tumefacción del brazo derecho. El diagnóstico se obtuvo con el estudio histopatológico. La evolución clínica fue buena seis meses después del tratamiento para tuberculosis.

Palabras clave. Tuberculosis, Mycobacterium tuberculosis, musculatura esquelética, bíceps braquial.

\section{ABSTRACT}

Primary skeletal muscle tuberculosis is an unusual and extremely rare clinical presentation, especially in immunocompetent patients. We present a 22 year-old patient with a swollen right arm in whom the diagnosis of tuberculosis was established by histology. Clinical response was good after six months with tuberculosis treatment.

KeYwords. Tuberculosis, Mycobacterium tuberculosis, skeletal muscle, brachial biceps.

\section{INTRODUCCIÓN}

La localización muscular de la tuberculosis (TB) es rara, sobretodo en pacientes inmunocompetentes. $\mathrm{Su}$ presentación es inusual, a menudo simula une lesión tumoral.

La resonancia magnética contribuye en esta forma de TB al diagnóstico que es esencialmente histopatológico. Se presenta un caso de TB aislada del músculo bíceps braquial.

I. Departamento de Neumología, Hospital Militar Avicena, Marrakech, Marruecos.

2. Departamento de Traumatología, Hospital Militar Avicena, Marrakech, Marruecos.

\section{REPORTE DEL CASO}

Varón de 22 años sin antecedentes importantes, y sin traumatismo previo, que acudió a nuestro hospital por dolor y una hinchazón de la región inferior del brazo derecho que había aumentado progresivamente durante los tres meses anteriores.

Al examen físico se observó una masa localizada en la parte inferior del brazo derecho, fluctuante y dolorosa a la palpación sin signos inflamatorios asociados.

En los exámenes auxiliares: hemograma con 6060 leucocitos por $\mathrm{mm}^{3}$, neutrófilos $56 \%$, linfocitos $29 \%$, hemoglobina $11 \mathrm{~g} / \mathrm{dL}$, plaquetas 292000 por $\mathrm{mm}^{3}$, proteína $\mathrm{C}$ reactiva $11 \mathrm{mg} / \mathrm{dL}$. La serología para el VIH fue negativa, y la radiografía de tórax fue normal.

La ecografía de partes blandas mostró una colección bilobulada hipoecoica, heterogénea, sin componente vascular, de $83 \mathrm{~mm}$ x $23 \mathrm{~mm}$ en la parte inferior del brazo derecho (Figura 1).

La resonancia magnética (RM) mostró una lesión de $89 \mathrm{~mm}$ x $28 \mathrm{~mm}$ x $29 \mathrm{~mm}$, heterogénea, en la parte inferior y externa del brazo derecho que tenía baja señal en T1, alta señal en T2 y con un componente tisular que 

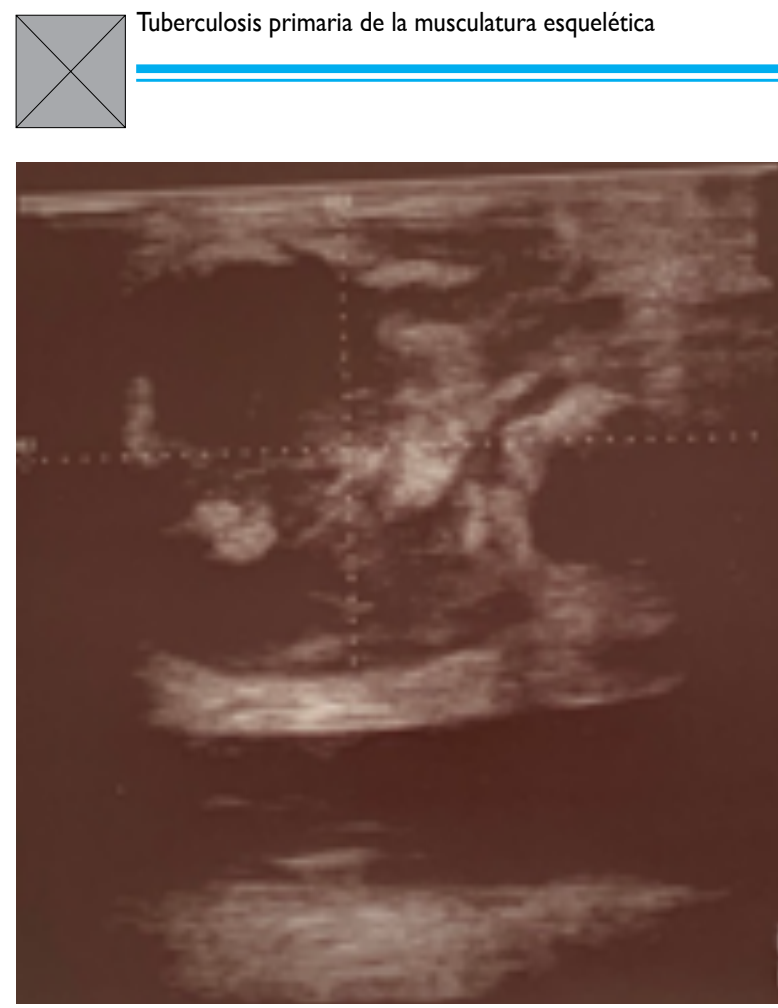

Figura I. Ecografía de partes blandas.

se realzó tras inyección de gadolinio. Había una discreta infiltración del tejido adiposo subcutáneo. No había evidencia de afectación ósea. La lesión era sugestiva de absceso o lesión tumoral (Figura 2).

Se realizó una punción ecoguiada con aguja fina, se obtuvo un líquido de aspecto purulento que resultó negativo para gérmenes comunes con la coloración de Gram, la tinción de Ziehl-Neelsen y el cultivo. Se

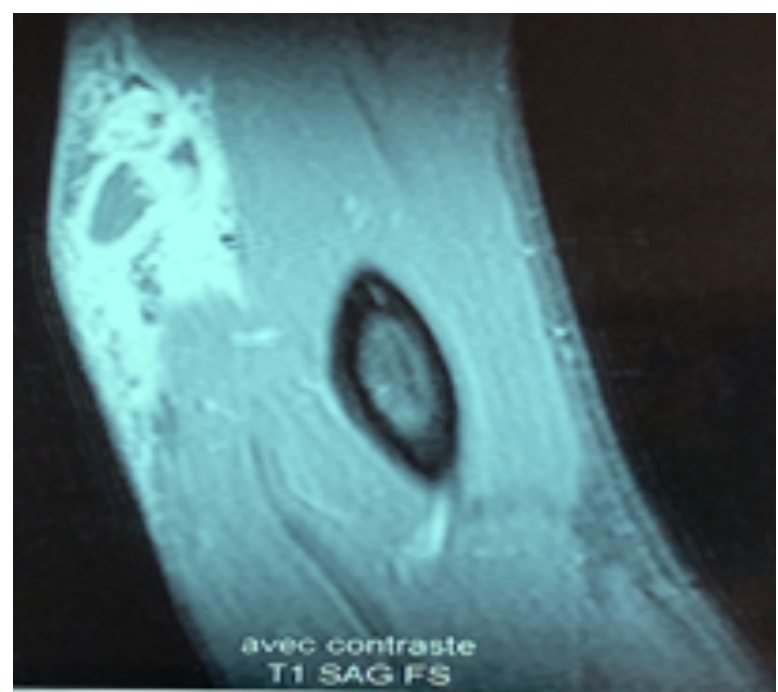

Figura 2. Imagen sagital de la resonancia magnética en TI. Lesión que capta contraste en la zona muscular.Al centro, sección del hueso húmero.

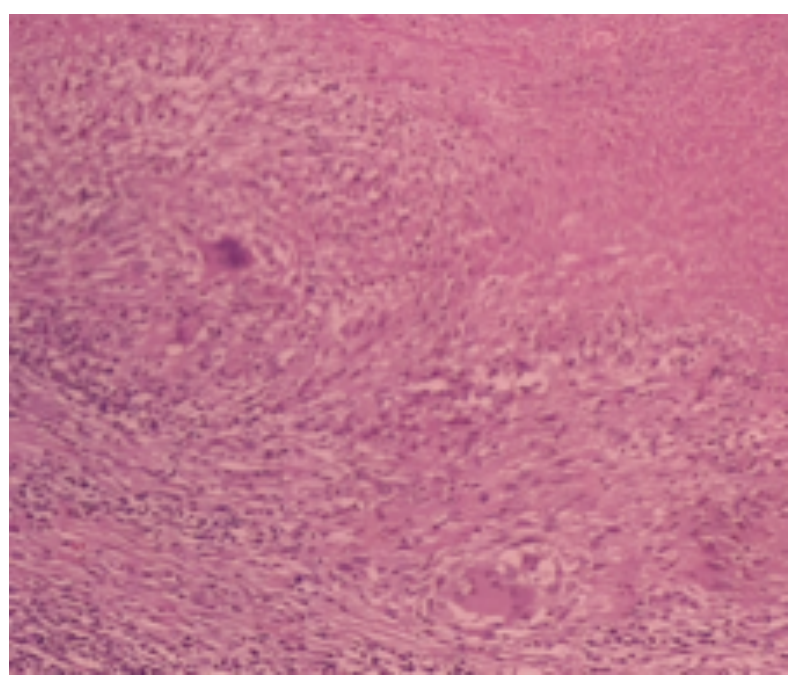

Figura 3. Estudio histopatológico: granulomas epitelioides necrotizantes.

decidió el abordaje quirúrgico de la lesión con drenaje y el estudio histopatológico del tejido tomado reveló la presencia de granulomas con células epitelioides y con necrosis caseosa (Figura 3).

Se inició tratamiento para TB con isoniacida, $300 \mathrm{mg} / \mathrm{d}$; rifampicina, $600 \mathrm{mg} / \mathrm{d}$; pirazinamida, $1500 \mathrm{mg} / \mathrm{d}$, y etambutol, $1200 \mathrm{mg} / \mathrm{d}$, los dos primeros meses, seguido de isoniacida y rifampicina hasta completar seis meses. La respuesta al tratamiento fue buena.

\section{DISCUSIÓN}

La tuberculosis es un problema mayor de salud pública en todo el mundo. Cerca de 10,4 millones de personas desarrollaron TB en 2016, y 1,7 millones murieron por esta enfermedad. ${ }^{1}$

En Marruecos, que es un país con TB endémica, las localizaciones extrapulmonares más frecuentes son la ganglionar, y la pleural.

Las manifestaciones osteomusculares se presentan en 1,0\%-5,2\% de los casos, ${ }^{2}$ mientras que la localización muscular aislada sin otras manifestaciones es excepcional.

La TB muscular afecta mayoritariamente a personas inmunodeprimidas, sobre todo personas con síndrome de inmunodeficiencia adquirida. ${ }^{3}$ Su patogénesis no está clara, se ha postulado que se debe a la diseminación hematógena de las lesiones tuberculosas, ser secundaria a una infección contigua desde una estructura subyacente o a una inoculación traumática directa. Así, 
se clasifica según su origen en primaria o secundaria. Nuestro paciente no tuvo evidencia clínica o radiológica de compromiso de otras estructuras o el antecedente de traumatismo que indicara una posible inoculación.

La musculatura esquelética no es un sitio favorable para el crecimiento y la multiplicación de Mycobacterium tuberculosis. Este tejido es caracterizado por su alto contenido de ácido láctico, su alta vascularización y flujo sanguíneo y por la ausencia de tejido reticuloendotelial y linfático. ${ }^{4}$

Las manifestaciones clínicas se suelen presentar de forma insidiosa, en ausencia de fiebre y síntomas generales. El diagnóstico se suele realizar en fases avanzadas por la presencia de abscesos fríos o fístulas. Las imágenes de tomografía computarizada o resonancia magnética sugieren el diagnóstico de tuberculosis muscular y son importantes para delimitar su extensión de la lesión y buscar la existencia de afectación ósea. El problema de estas formas de tuberculosis radica en la dificultad para llegar a su diagnóstico definitivo, ya que tanto los síntomas clínicos como las pruebas de imagen pueden ser inespecíficos.

Para la obtención del diagnóstico en la tuberculosis se debe obtener muestras de líquidos y/o tejidos que sean accesibles mediante punción con aguja fina, realizando baciloscopia, cultivo y PCR, llegando si es preciso a la biopsia del tejido afectado si la punción no es diagnóstica. ${ }^{5}$ Por ser de características paucibacilares, la detección del bacilo ácido-alcohol-resistente (BAAR) en el estudio directo se obtiene raramente, como en nuestro caso.

El estudio histopatológico de tejidos tomados por biopsia muestra los típicos granulomas necrotizantes que contienen macrófagos, linfocitos y células de Langhans. Su presencia tiene una elevada especificidad y podría justificar la decisión de iniciar tratamiento antituberculoso. Así, el paciente presentado obtuvo una mejoría clínica con tratamiento.

En los últimos años se ha detectado ADN de $M$. tuberculosis mediante PCR en estas lesiones, aunque de forma inconsistente. ${ }^{6}$

El tratamiento de estas formas de tuberculosis no difiere de las pautas de tratamiento de las formas pulmonares. Se recomienda utilizar los mismos regímenes de antibióticos con una duración de seis meses. El pronóstico es bueno con el tratamiento adecuado.

En conclusión, este caso presentado sugiere que se debe evocar el diagnostico de tuberculosis de la musculatura esquelética ante un hinchazón dolorosa del brazo, o de una zona muscular, sobre todo en individuos de una región país endémica de tuberculosis, aunque la presentación clínica es inusual.

\section{REFERENCIAS BIBLIOGRÁFICAS}

I. World Health Organization. Global tuberculosis control.WHO Report 2016.

2. Abdelwahab IF, Bianchi S, Martinoli C, Klein M, Hermann G. Atypical extraspinal musculoskeletal tuberculosis in immunocompetent patients: part II, tuberculous myositis, tuberculous bursitis, and tuberculous tenosynovites. Can Assoc Radiologists J. 2006;57(5):278-286.

3. Osorio J, Barreto J, Benavides J, Lopez O, Cuenca A, García E. Piomiositis tuberculosa en un paciente inmunsuprimido. Biomédica. 2016;36(supl I):23-8.

4. Perez-Alonso AJ, Husein-El Ahmed H, Duran CP, Caballero-Marcos $\mathrm{L}$, Ramon JAP. Tuberculose musculaire isolée. Médecine et maladies infectieuses. 20II; 4I:559-564

5. Ramírez-Lapausa M, Menéndez-Saldaña A, Noguerado-Asensio A Tuberculosis extrapulmonar, una revisión. Rev Esp Sanid Penit. 2015; 17 : 3-II.

6. Tan MF, Chan SH, Tan WC. Comparative usefulness of PCR in the detection of Mycobacterium tuberculosis in different clinical specimens. Molecular Diagnosis. 1997;46:164-169.

CORRESPONDENCIA: Dr. Bouchentouf Rachid bouchentouf_rachid@yahoo.fr

FECHA DE RECEPCIÓN: I de abril de 2019.

FECHA DE ACEPTACIÓN: 20 de mayo de 2019.

CONFLICTO DE INTERÉS: Ninguno, según los autores.

FINANCIAMIENTO: Por los autores. 